\title{
Thermal Control and Heat Accounting: Economics Related to Service Time and Building Insulation
}

\author{
Chiara Marafioti $^{1}$, Stefano Bergero ${ }^{2 *}$, Paolo Cavalletti ${ }^{1}$, Annalisa Marchitto ${ }^{1}$ \\ ${ }^{1}$ DIME - Department of Mechanical Engineering, Polytechnic School, University of Genoa, Via all'Opera Pia 15A, Genoa, \\ Italy \\ ${ }^{2}$ DAD - Department of Architecture and Design, Polytechnic School, University of Genoa, Stradone S.Agostino, 37, Genoa, \\ Italy
}

Corresponding Author Email: stefano.bergero@unige.it

https://doi.org/10.18280/ti-ijes.632-402

Received: 16 January 2019

Accepted: 21 April 2019

\section{Keywords:}

cost-benefit analysis, heat metering, heat regulation, residential building energy efficiency

\begin{abstract}
The aim of the paper is to evaluate the economic convenience derived from the installation of thermal control and heat accounting devices in building units served by central heating plants, except for cases of technical impossibility or not economic viability. A statistical analysis concerning the Italian residential building park has been carried out with reference to the service time and insulation level. Devices installation costs have been obtained from different regional price lists of the Italian territory. Taking as a reference a typical Italian housing unit, a cost-benefit analysis in terms of Net Present Value (NPV) indicator is carried out according to the UNI EN 15459 standard, considering the cash flows over a period of 30 years, as required by EU regulations. Results show that for buildings located in $\mathrm{D}, \mathrm{E}$ and $\mathrm{F}$ climatic zones within the Italian territory there is no economic convenience if the number of using days per year is lower than a certain threshold which is considerably high in case of holyday houses. In terms of thermal building insulation, the present study shows an economic advantage in investing in thermoregulation and heat accounting devices for existing un-refurbished buildings; this consideration could not be extended to buildings already undergoing major renovation works.
\end{abstract}

\section{INTRODUCTION}

This paper is inspired by the application of the Directive 2012/27/EU [1] and its Italian transposition through the Legislative Decree 102/2014 [2], which states that " to measure the actual heat, cooling or hot water consumption for each housing unit, individual meters are installed to the extent that it is technically feasible, cost-effective and proportionate compared to potential energy savings". Cost-efficiency can be assessed with reference to the methodology specified in UNI EN 15459 standard. Any cases of technical impossibility for the installation of the above-mentioned accounting systems must be written out in a specific technical report by a designer or authorized engineer".

The legislator's goals are both to seek energy efficiency and guarantee centralized plants to be as flexible as the autonomous ones, that allows the users to pay on consumption and consequently incentives savings. Before the entry into force of the Decree 102/2014 costs have been usually fixed on percentage of installed thermal power or on millesimal share of ownership or on the radiant surface. Only few buildings had the chance to withdraw and pay energy bills based on individual users' actual consumptions, as occurs in case of independent heating. This condition did not reward the citizens' virtuous behavior with a proportional economic benefit. Therefore, there was no incentive in energy saving, by improving the envelope insulation or turning off the radiators when the house is not inhabited, for instance.

Regardless of the obligations established by Legislative Decree 102/2014, thermoregulation and direct/indirect heat accounting for flats is always advisable. The previous Presidential Decree 412/1993 [3] already imposed a thermoregulation and heat metering design for each apartment in new buildings, with temperature control and heat accounting systems for each housing unit. Directive 2012/27/EU and the consequent Legislative Decree 102/2014 don't force existing buildings to adopt such systems: the plant refurbishment must be paid back by related energy savings; otherwise the requirement can be rejected due to a not "efficient in terms of costs" reason. A lot of Italian citizens did not perceive the usefulness of asking a qualified technician to verify whether they could potentially gain an exemption from regulatory imposition. An ANACI - Censis Servizi study of 2009 [4] demonstrated it: about $35 \%$ of the citizens interviewed after the installation of the accounting systems declared an increase in heating costs.

Literature survey reveals some studies concerning heat metering systems in buildings. Most of the papers concern heat metering and energy efficiency retrofit of existing residential buildings in northern heating areas of China; such policy was organized and implemented in a large scale by the local government in the years from 2008 to 2013 [5-8]. Another series of papers deals with the problem related to measurement errors of indirect heat allocators [9-11]. A review concerning the state-of-the-art in building energy metering and environmental monitoring, including their social, economic, environmental and legislative drivers is available in [12]. Only few studies regarding the economic convenience and technical feasibility of thermal control and heat accounting device installations are available. In [13] a brief analysis of the main 
features of direct and indirect heat metering and sub-metering systems is discussed and the related cost-benefit analysis of the economic efficiency is presented. In [14] a preliminary study on the economic convenience of thermoregulation and heat accounting devices installation based on different climatic conditions of the Italian territory has been carried out by the Authors.

In this work, a more in-depth analysis, conducted on statistical basis, is presented: cost-benefit analysis considers the influence of two significant parameters that affect the building energy need, such as the service time and the global heat transmission coefficient related to the insulation level of the opaque and glazed envelope. As a case study, the economic impact of thermoregulation and indirect heat accounting devices installation has been carried out with reference to the average Italian housing unit and considering both the presence and the absence of tax-free discounts, nowadays available. UNI EN 15459 standard [15] has been applied calculating the Net Present Value (NPV) indicator with 30 years period cash flows, as appointed by EU Regulation 244/2012 [16].

\section{CONSIDERATIONS ON TEMPERATURE CONTROL AND HEAT METERING DEVICES}

The analysis has been conducted referring to the typical Italian building unit with central heating plant [14], whose national average data are obtained from the 2011 ISTAT Census [17] in terms of useful area per unit $\left(76.8 \mathrm{~m}^{2}\right)$, radiators per unit (4.45), number of apartments (30), heated volumes, type of plant and climate zone. As for the plant, indirect metering system is considered because it is the most common technology in Italy.

Table 1 provides the classification of the Italian territory in climate zones from A to D, based on Heating Degree-Days (HDD) [18], according to the Presidential Decree 412/1993 [3] and the Italian population distribution, source CRESME [19].

Table 1. Population distribution in Italian climatic zones

\begin{tabular}{ccccccc}
\hline & \multicolumn{7}{c}{ Climatic Zone } \\
\cline { 2 - 7 } & $\mathrm{A}$ & $\mathrm{B}$ & $\mathrm{C}$ & $\mathrm{D}$ & $\mathrm{E}$ & $\mathrm{F}$ \\
$\mathrm{HDD}\left[{ }^{\circ} \mathrm{C} \cdot\right.$ days $]$ & $\leq 600$ & $600-$ & $900-$ & $1,400-$ & $2,100-$ & $>3,000$ \\
& & 900 & 1,400 & 2,100 & 3,000 & \\
Heating days & 105 & 121 & 137 & 166 & 183 & 200 \\
$\quad$ Indoor to & $<$ & $5.0-$ & $6.6-$ & $8.4-$ & $11.5-$ & $>15.0$ \\
outdoor daily & 5.7 & 7.4 & 10.2 & 12.7 & 16.4 & \\
$\quad \begin{array}{c}\text { mean } \\
\text { temperature }\end{array}$ & & & & & & \\
difference $\left[{ }^{\circ} \mathrm{C}\right]$ \\
$\begin{array}{c}\text { Population } \\
\text { Thousands] }\end{array}$ & 23 & 3,193 & 12,496 & 14,616 & 25,962 & 1,598 \\
Distribution [\%] & 0.03 & 5.52 & 21.59 & 25.25 & 44.85 & 2.76 \\
\hline
\end{tabular}

About $48 \%$ of Italian population lives in $\mathrm{E}$ and $\mathrm{F}$ climatic zones, while the remaining $52 \%$ in A to D zones. Most of Italian people (about $45 \%$ ) live in $\mathrm{E}$ zone. Therefore, it is correct to attribute the heating average cost for dwelling, equal to $1,111 €$, to an average building unit located in $\mathrm{E}$ zone with 2,521 HDD. Assuming heating costs proportional to the difference in temperature between indoor and outdoor, and consequently to the HDD, the heating costs and savings for the other climatic zones can be extrapolated. Heating costs and savings have been achieved operating by analogy with the standardized assessment method proposed in [20], that allows to quantify annual specific gross primary energy saving from a retrofit intervention through the determination of savings related to a single physical unit of reference without direct measurements.

The basic concept is that low energy requirements of the apartment lead to low economic savings compared to thermoregulation and heat accounting devices installation costs, which are almost independent from energy needs, and therefore there is no economic advantage.

The total adjustment cost per average building unit in 10 years for temperature control and heat metering devices installation is about $1,070 €$, as showed in detail by the Authors' previous paper [14]. The total amount comprises both the device and installation costs (twin speed-controlled circulator, thermostatic valves and meters), technical project, work supervision, audit, final test, condominium division calculation, VAT included. It also considers operational, maintenance and disposal costs in percentage of initial investment, included annual reading charges and devices lifespan. Prices were deducted from the Price List Works Plants and Construction 2016 of Liguria Region [21] and from the Ministerial Decree 140/2012 [22]. Economic data of maximum lifespan, annual preventive maintenance and disposal costs were obtained from UNI EN 15459 Annex A [15]. Note that as a precautionary measure, fuel costs related to domestic hot water production and cooking use have not been spun off from the heating cost.

In [14], the climatic zone influence was investigated for both absence and presence of tax refund incentives considering minimum (10\%) and maximum (16 \%) savings obtainable by temperature control and heat metering devices implementation. The results showed that, without tax incentives, in A to D climatic zones of the Italian territory the economic convenience cannot be reached, while such interventions may be convenient in $\mathrm{E}$ and $\mathrm{F}$ climatic zones.

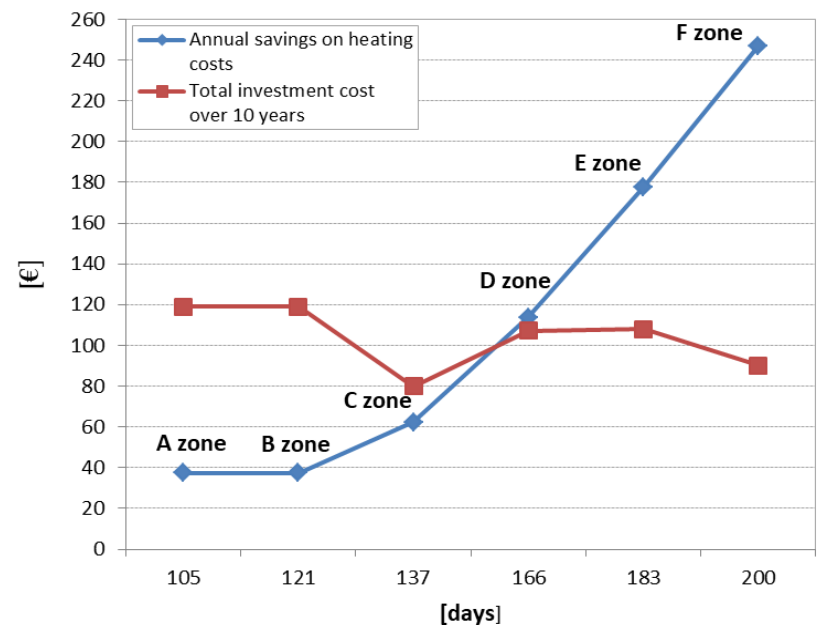

Figure 1. Comparison between annual savings and annual investment costs on a 10 years period

A first step of the present work concerns a deepening of the climatic zones influences. The results are summarized in Figure 1, which shows the investment economic convenience over a period of 10 years for different climatic zones: annual savings (blue line), calculated from ISTAT data and considering an energy need reduction of $16 \%$, are compared with annual costs (red line), obtained evaluating the total expense on 10 years. In this time period, all costs, inflation effects and residual economic values of life for devices with a 
useful life longer than 10 years have been considered on nowadays basis. Initial costs of $1,070 €$, deducted from Liguria Region price list [21], are attributed to the zone D. Data for the other climatic zones are provided by some price lists of the Italian territory: Trentino Alto Adige (F zone) [23], Piedmont (E zone) [24], Campania (C zone) [25] and Sicily (A and B zones) [26].

The graph reveals that, while the investment cost is practically constant in the various climatic zones, the economic saving significantly increases from A zone to $\mathrm{F}$ zone. The higher benefit is reached in $\mathrm{E}$ and $\mathrm{F}$ zones because of the very large ratio between annual savings and costs; on the contrary, in A, B and C zones, costs do not tangibly support the investment: nowadays their installation is quite unadvisable. The Liguria Region, included in D zone, is characterized by intermediate conditions where costs and benefits are roughly equivalent.

\section{EVALUATION METHOD}

This chapter describes the method used to determine the average energy need of typical Italian housing units.

Analysis is based on statistical data of ISTAT Census [17], ENEA [27], CRESME [19] and TABULA [28], concerning thermal and geometric characteristics of the Italian building park and of its technical elements. Existing buildings are classified and related to the construction period which determines the insulation level, depending on the subsequent Italian laws in the field of buildings energy efficiency: before 1976 [29], 1976-1991 [30], 1992-2005 [31]. Each legislative measure imposed minimum performance requirements on buildings energy efficiency leading to the adoption of different construction methods and technical elements.

The seasonal thermal energy need represented with the capital letter $E$ entering the production system of a thermal zone, neglecting solar and internal gains, can be calculated using the simplified following formula provided by UNI/TS 11300-1 technical specification [32]:

$E=H_{h t} \cdot \Delta T \cdot \tau / \eta$

$H_{h t}$, global heat transfer coefficient of the thermal zone

$\Delta T$, difference between indoor and outdoor temperature, depending on the climatic zone

$\tau$, usage time of the housing unit

$\eta$, plant efficiency including thermal losses due to emission, regulation, distribution and production subsystems.

$H_{h t}$ coefficient considers both ventilation and transmission heat losses:

$H_{h t}=H_{v e}+H_{t r}$

$H_{v e}$, ventilation coefficient of the thermal zone

$H_{t r}$, transmission coefficient of the thermal zone.

UNI/TS 11300-1 standard provides the following formula to evaluate the ventilation heat transfer coefficient $H_{v e}$ in case of natural ventilation:

$H_{v e}=0.34 n V_{u}$

$n$, air renewal rate, equal to $0.3 \mathrm{~h}^{-1}$

$V_{u}$, net volume of the thermal zone.

$H_{t r}$ coefficient is calculated according to UNI EN ISO
13789 [33] and UNI EN ISO 13370 [34], using the following equation:

$H_{t r}=H_{D}+H_{g}+H_{U}+H_{A}$

$H_{D}$, direct heat transfer coefficient by transmission to the external environment

$H_{g}$, steady-state heat transfer coefficient by transmission to the ground

$H_{U}$, heat transfer coefficient by transmission through unconditioned spaces

$H_{A}$, heat transfer coefficient by transmission to adjacent buildings.

$H_{t r}$ coefficient includes the effect of linear and punctual thermal bridges. In the present study, for reasons of simplicity, the contribution of the thermal bridges is neglected since thermal and geometric parameters were derived from statistical analyses on the Italian building estate and the mean standard consumption already include the real energy need.

$H_{x}$ coefficient, representing $H_{D}, H_{g}, H_{U}$ or $H_{A}$, is evaluated as:

$H_{x}=\sum_{i} A_{i} U_{i} b_{t r, x, i}$

$A_{i}$, gross projected area of the $\mathrm{i}^{\text {th }}$ element (opaque or transparent) which is part of the exchange surface of the building envelope

$U_{i}$, thermal transmittance of the $\mathrm{i}^{\text {th }}$ element

$b_{t r, x, i}$, adjustment factor between interior and adjacent zone to $i^{\text {th }}$ element, derived from UNI/TS 11300-1.

The analysis of ventilation coefficient influence on building energy need is not relevant, as most of the Italian building stock is characterized by natural ventilation; on the contrary, the transmission coefficient influence is significant, since buildings are provided with different geometric ratios and degrees of insulation of the opaque and glazed envelope in different construction periods.

A significant indicator of building envelope energy performance is the mean heat transmission coefficient $H_{T}^{\prime}$ of the building, which was recently introduced by the Ministerial Decree June 26, 2015 [35], defined as follows:

$H^{\prime}{ }_{T}=H_{t r} / \sum_{i} A_{i}$

\section{RESULTS AND DISCUSSION}

EU Regulation 244/2012 [16] provides the method for evaluating the optimal energy requirements of buildings from both a technical and an economic point of view. Calculation of the cost effectiveness in buildings energy performance field is carried out by UNI EN 15459 [15] with the use of the Global Cost (GC) method. The cash flows over a period of 30 years are considered. The methodology for the determination of the Net Present Value (NPV) is reported in detail in [36].

The hypothesis of tax deduction incentives absence is necessary to verify the efficiency in terms of costs, since many citizens may not benefit from tax deductions: therefore, take them into account in a general audit valid for the whole building, as suggested by Ministerial Italian FAQ [37], is not reasonable. However, if the condominium assembly deliberates to install thermoregulation and heat metering devices regardless of legal obligations from Legislative Decree 102/2014, a $50 \%$ tax deduction must be considered, as 
actually permitted by current national legislation in terms of building renovations.

In this chapter, the economic convenience of thermal control and heat accounting devices installation has been analysed as a function of two operating parameters of Eq (1): service time and thermal and geometric characteristics depending on the constructive period.

Thermostatic valves installation leads to the regulation subsystem conversion from "only climatic" to "single room + climatic", with a consequent improvement of the regulation efficiency $(10 \% \div 16 \%$ reduction of building energy consumption, as proposed by the ENEA Report RdS/PAR 2014/081 analysis [38] and by UNI/TS 11300-2:2014 technical specification application [39]).

\subsection{Analysis in terms of service time}

The economic convenience shown in colder climatic zones [14] may not actually exist in the case of occasional occupation buildings such as mountain holiday homes. These buildings are often used for few days (about 15-30) per year, but the central heating system remains operative for the entire winter season to ensure minimum temperatures inside the apartments and prevent local breakages in the plant. It follows that the expenditure for the involuntary consumption may be higher than the one associated to the voluntary consumption of individual building units, with the consequent reduction of the economic convenience in installing thermoregulation and heat accounting devices.

The purpose of this study is to determine the minimum number of days per year for D, E and F climatic zones under which investing in thermoregulation and heat accounting systems is not convenient. The $\mathrm{A}, \mathrm{B}$ and $\mathrm{C}$ climatic zones have been excluded from this analysis since the previous Authors' article [14] demonstrated the absence of convenience in these areas even if the apartment was continuously used in the heating season. Results are reported in Figure 2.1

Figures 2 (a), 2 (b), 2 (c) show three-dimensional graphs in which cumulated cash flows, calculated considering tax deduction and energy saving of $16 \%$, are reported for an evaluation period of 30 years as a function of the number of using days. Figure 2 (a) refers to D climatic zone, Figure 2 (b) refers to E climatic zone and Figure 2 (c) refers to F climatic zone.

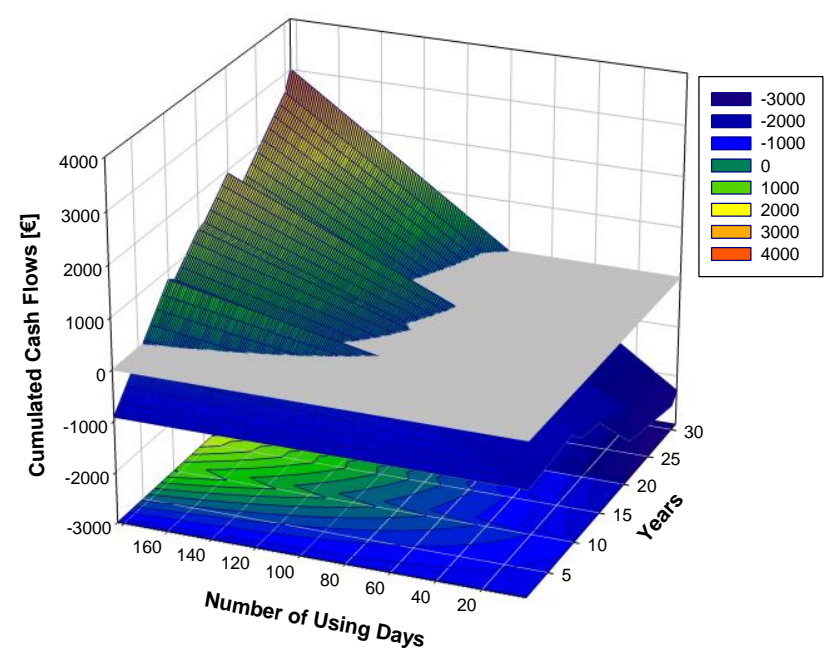

Figure 2 (a). Cumulated cash flows versus using time for D climatic zone

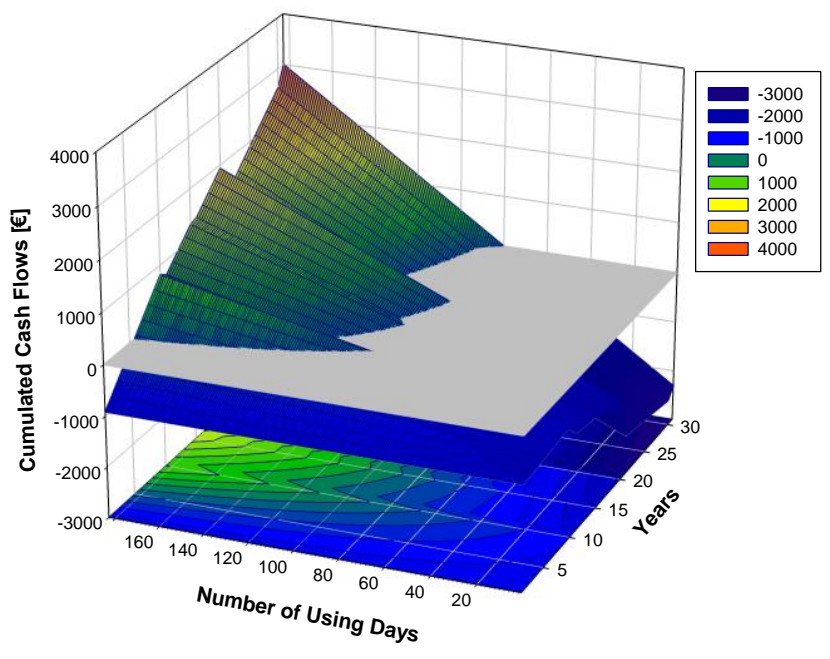

Figure 2 (b). Cumulated cash flows versus using time for E climatic zone

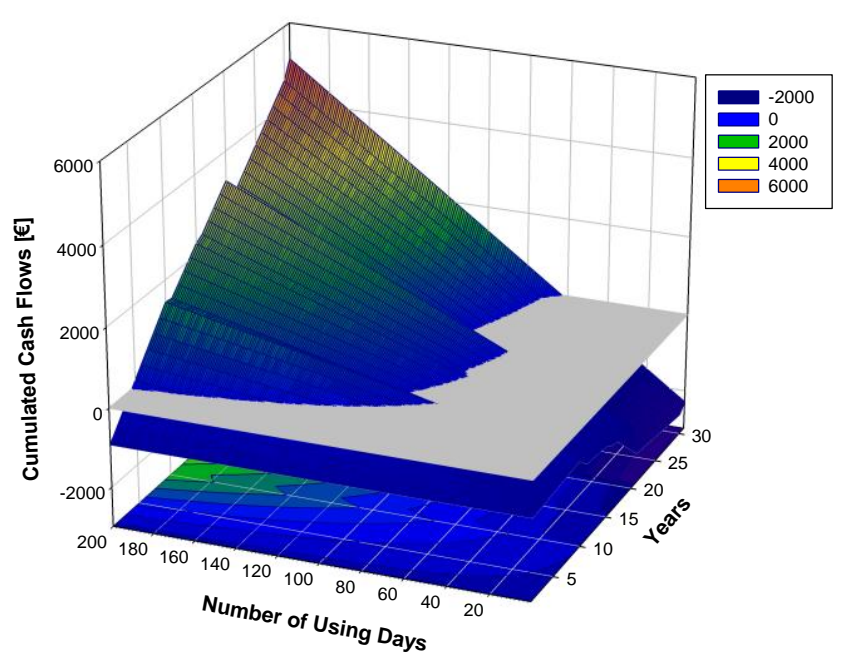

Figure 2 (c). Cumulated cash flows versus using time for $\mathrm{F}$ climatic zone

They reveal that there is no benefit from investing in thermoregulation and heat accounting in any climatic zone if the number of using days is lower than a certain threshold.

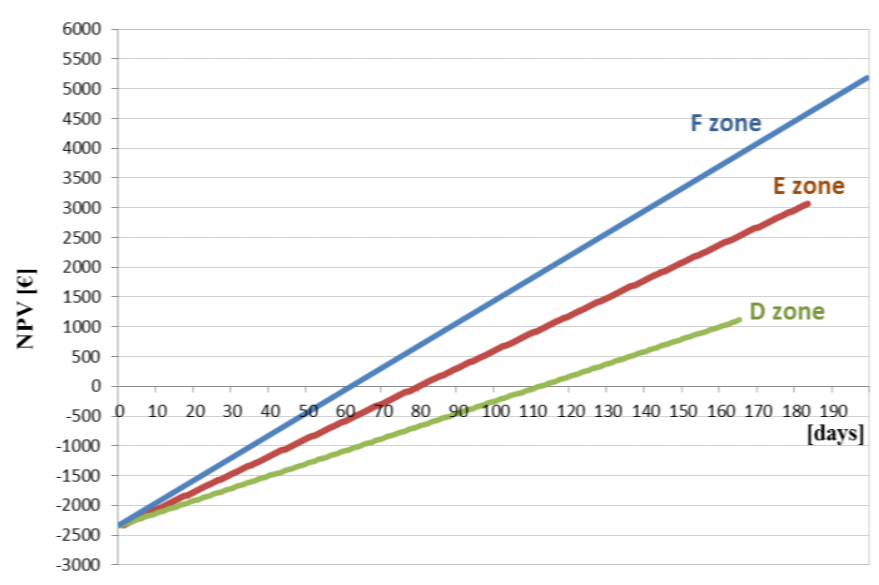

Figure 3. NPV versus number of using days at the end of $30^{\text {th }}$ year 
Figure 3 shows the Net Present Value (NPV) at the end of $30^{\text {th }}$ year versus the number of using days for each climatic zone. Note that the minimum number of using days to achieve economic convenience is 111 in the $\mathrm{D}$ zone, 78 in the $\mathrm{E}$ zone and 61 in the $\mathrm{F}$ zone; curves stop at different days because they are related to the different duration of the heating season, as shown in Table 1.

An improvement in the energy efficiency of a heating system in $\mathrm{E}$ or $\mathrm{F}$ zone will result in greater annual energy savings linked to higher consumption: this clearly shows that the number of using days to get economic convenience is lower.

\subsection{Analysis in terms of performance of building technical elements}

In the last decade in Italy a strong incentive policy with percentages between $50 \%$ and $65 \%$ in terms of tax deduction, has been promoted encouraging energy improvement of building envelope and plant components. The Italian building heritage can be divided on the basis of constructive periods using Italian energy laws as boundaries: the first energetic Law 373/1976 [29], which involves only envelope transmittance minimum values to be respect, the Law 10/1991 [30], which considers for the first time the entire building-plant system, and the Legislative Decree 192/2005 [31] and its frequent modifications and integrations which lines up Italian energy rules to European ones. Only buildings built before 2005 are considered in the present analysis, because more recent buildings are already equipped with thermoregulation and heat metering devices for obligation.

A significant indicator of the degree of building insulation is the mean heat transmission coefficient $H_{T}^{\prime}$ [40] defined byEq (6). The following parameters are set in applying Eq (1): the using time $\tau$ corresponding to the complete heating season days and the temperature difference $\Delta T$ for each climatic zone, obtained from the ratio between the HDD and the number of heating days as shown in Table 1. According to UNI/TS $11300-2$ [39], the 0.768 value of the plant efficiency $\eta$ is assumed, corresponding to a standard plant with radiators as emission subsystem, climatic sensor as regulation subsystem, vertical distribution with upright columns and traditional modulating boiler as production subsystem. Unlike the insulation level of constructive elements, the efficiency $\eta$ does not change according to the construction period, since heating systems and boilers may have been renewed over the years. A future study will regard the incidence of this parameter. It follows that only the $H_{T}^{\prime}$ parameter influences the energy requirement using $\mathrm{Eq}(1)$.

Table 2. Common data to all buildings, regardless of climatic zone and construction age

\begin{tabular}{cc}
\hline \multicolumn{2}{c}{ Standard apartment } \\
\hline Average surface of the plan view & $76.8 \mathrm{~m}^{2}$ \\
Long side of plan view & $9.6 \mathrm{~m}$ \\
Short side of plan view & $8 \mathrm{~m}$ \\
Average number of rooms & 4.45 \\
Room height & $3 \mathrm{~m}$ \\
Maximum total dispersing surface & $259.2 \mathrm{~m}^{2}$ \\
Volume & $230.4 \mathrm{~m}^{3}$ \\
Net volume & $195.8 \mathrm{~m}^{3}$ \\
\hline
\end{tabular}

The analysis concerns the typical Italian dwelling, characterized by geometrical parameters reported in following
Table 2 and by the mean heat transmission coefficient values reported in Table 3, derived from ISTAT [17], CRESME [19] and TABULA [28]; for each climatic zone and constructive period, it has been possible to calculate an average standard value of $H_{T}^{\prime}$ parameter. Calculation are carried out for climatic zones D, E, F, for which the economic convenience of thermoregulation and heat accounting devices installation was demonstrated; herein, the suitability of the investment according to the type of building envelope is discussed.

Table 3. $\mathrm{H}_{\mathrm{T}}$ coefficient as a function of climatic zone and construction age for existing buildings

\begin{tabular}{cccc}
\hline $\mathbf{H}^{\prime}{ }_{\mathbf{T}}$ & $\begin{array}{c}\text { Before } \\
\mathbf{1 9 7 6}\end{array}$ & $\begin{array}{c}\text { Between 1977 } \\
\text { and 1991 }\end{array}$ & $\begin{array}{c}\text { Between 1992 } \\
\text { and 2005 }\end{array}$ \\
\hline D zone & 1.86 & 1.78 & 1.78 \\
E zone & 1.42 & 1.45 & 1.45 \\
F zone & 1.23 & 1.23 & 1.23 \\
\hline
\end{tabular}

Building energy need of the typical housing unit has been calculated from Table 3 using formulas from (1) - to (6); results have been compared with the minimum energy need to have economic convenience. The lower is the $H_{T}^{\prime}$ limit value derived from calculations, the higher is the probability the installing of thermoregulation and heat accounting systems result convenient. Calculations show that the level of insulation for existing buildings located in D, E and F climatic zones is so low that the investment in thermoregulation and heat accounting systems is always convenient in presence of $50 \%$ tax deduction.

On the contrary, the economic convenience may be not appropriate if existing buildings have been subjected to energy refurbishment. Mandatory limits are very tight and refurbished buildings might present an appropriately high degree of thermal insulation. The related low amount of energy need might result in a less profitable installation of thermoregulation and heat accounting systems.

As an example, using thermal transmittance mandatory limits provided by the Ministerial Decree June 26, 2015 [35] for both opaque and glazed envelope, the legal $H_{T}^{\prime}$ limit value has been calculated for each climatic zone and constructive period. Results are reported in Figure 4 (a), 4 (b) and 4 (c) for different constructive periods: respectively before 1976, between 1977 and 1991 and between 1992 and 2005. Limit values of $H_{T}^{\prime}$ (blue lines) have been compared with the minimum value of the $H^{\prime}$ to have economic convenience (red lines), obtained from cost-benefit analysis.

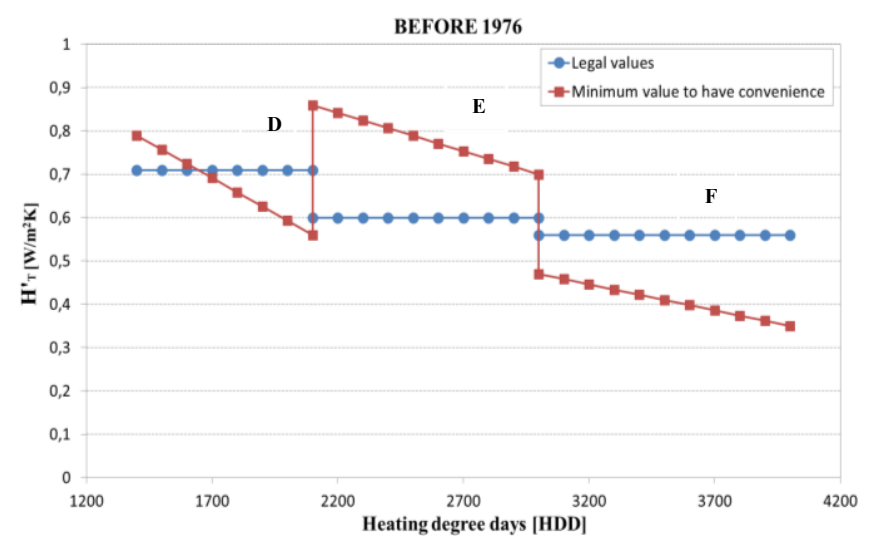

Figure 4 (a). Comparison between minimum $\mathrm{H}_{\mathrm{T}}$ values to obtain economic convenience and legal values (before 1976) 


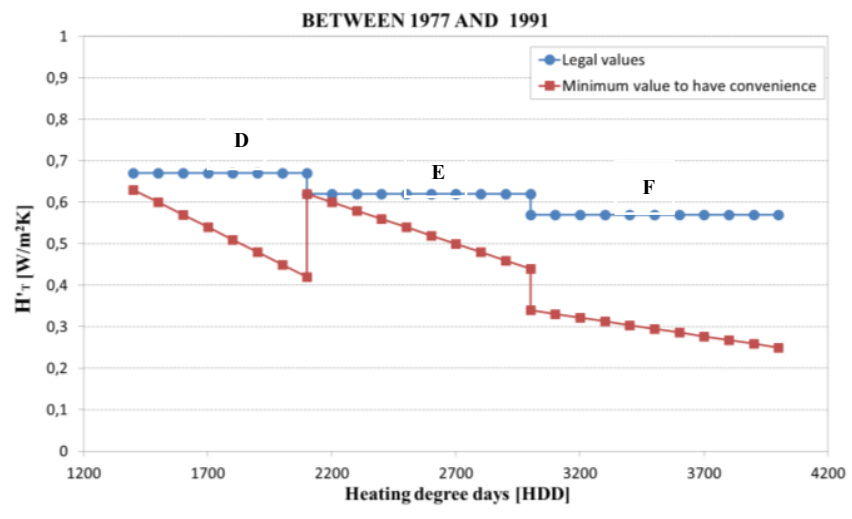

Figure 4 (b). Comparison between minimum $\mathrm{H}_{\mathrm{T}}$ values to obtain economic convenience and legal values (1976-1991)

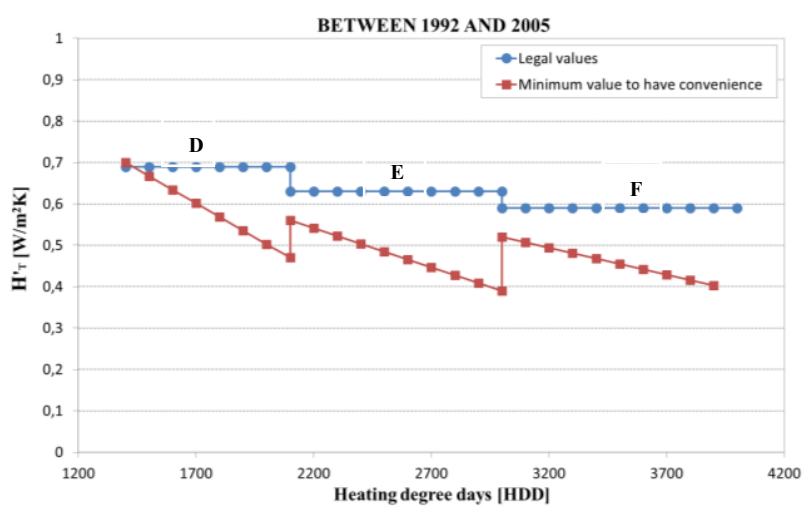

Figure 4 (c). Comparison between minimum $\mathrm{H}_{\mathrm{T}}$ values to obtain economic convenience and legal values (1992-2005)

If the blue line lowers the red one, the installation of thermoregulation and heat meter devices is not advisable, since thermal losses of building envelope are lower than the minimum value of $H_{T}^{\prime}$ to have economic convenience: this behaviour occurs in $\mathrm{D}$ and $\mathrm{E}$ climatic zones for buildings constructed before 1976 (Figure 4 (a)).

\section{CONCLUSIONS}

In the present paper, the cost-effectiveness of installing thermoregulation and heat accounting systems has been assessed by statistical analysis according to the requirements provided by the Italian legislation. The main conclusions are the following.

Without tax incentives, in climatic zones below 2100 HDD (A to D of Italian territory) the absence of cost efficiency has been verified, being NPV value lower than the initial investment cost; the improvement maybe convenient over $2100 \mathrm{HDD}$ (E and $\mathrm{F}$ zones). With tax incentives the investment may be convenient also between 1400 and 2100 HDD (D zone).

In climatic zones $\mathrm{D}, \mathrm{E}$ and $\mathrm{F}$ there is no economic convenience if the number of using days per year lowers a certain threshold which is considerably high and not pertinent in case of holiday homes.

The minimum value of the mean heat transmission coefficient $H_{T}^{\prime}$ for which the investment is convenient has been calculated for climatic zones D, F and E. There is economic advantage in investing in thermoregulation and heat accounting devices for existing un-refurbished buildings, regardless to the climatic zone and the construction period in presence of $50 \%$ tax deduction. On the contrary, economic convenience is not certain in case of buildings already undergoing major renovation works; this behaviour occurs for $\mathrm{D}$ and $\mathrm{E}$ climatic zones in case of buildings constructed before 1976.

\section{ACKNOWLEDGMENT}

This research was funded by the research project PRA2016University of Genoa.

\section{REFERENCES}

[1] European Parliament, Directive 2012/27/EU of the European Parliament and of the Council of 25 October 2012, on energy efficiency, amending Directives 2009/125/EC and 2010/30/EU and repealing Directives 2004/8/EC and 2006/32/EC, 2012.

[2] Legislative Decree 4 July 2014, No. 102, Implementation of Directive 2012/27/EU on energy efficiency, amending Directives 2009/125/EC and 2010/30/EU and repealing Directives 2004/8/EC and 2006/32/EC, Italy 2014.

[3] Decree of President of the Republic 26 August 1993, No. 412, Regulation laying down rules for design, installation, operation and maintenance of thermal installations of buildings for the purpose of containment of energy consumption, in implementation of art. 4, par. 4 of the Law of 9 January 1991, no. 10, Italy, 1993,

[4] Life in condominium: litigation and energy saving. ANACI-CENSIS, Italy, Rep. 3, 2009.

[5] Zhao J, Wu Y, Zhu N. (2009). Check and evaluation system on heat metering and energy efficiency retrofit of existing residential buildings in northern heating areas of china based on multi-index comprehensive evaluation method. Energy Policy 37(6): 2124-2130. https://doi.org/10.1016/j.enpol.2008.11.044

[6] Yan D, Zhe T, Yong W, Neng Z. (2011). Achievements and suggestions of heat metering and energy efficiency retrofit for existing residential buildings in northern heating regions of China. Energy Policy 39(9): 46754682. https://doi.org/10.1016/j.enpol.2011.07.004

[7] Bao L, Zhao J, Zhu N. (2012). Analysis and proposal of implementation effects of heat metering and energy efficiency retrofit of existing residential buildings in northern heating areas of China in "the 11th Five-Year Plan" period. Energy Policy 45: 521-528. https://doi.org/10.1016/j.enpol.2012.02.065

[8] Lu S, Feng W, Kong X, Wu Y. (2014). Analysis and case studies of residential heat metering and energy-efficiency retrofits in China's northern heating region. Renewable and Sustainable Energy Reviews (38): 765-774. https://doi.org/10.1016/j.rser.2014.07.015

[9] Ficco G, Celenza L, Dell'Isola M, Vigo P. (2016). Experimental comparison of heat allocation systems in a residential building at critical conditions. Energy and Buildings 130:

$477-487$ https://doi.org/10.1016/j.enbuild.2016.08.068

[10] Arpino F, Cortellessa G, Dell'Isola M, Ficco G, Marchesi R, Tarini C. (2016). Influence of installation conditions on heating bodies thermal output: Preliminary experimental results. En. Proc. 101: 74-80. 
https://doi.org/10.1016/j.egypro.2016.11.010

[11] Dell'Isola M, Ficco G, Arpino F, Cortellessa G, Canale L. (2017). A novel model for the evaluation of heat accounting systems reliability in residential buildings. Energy and Buildings 150: 281-293. https://doi.org/10.1016/j.enbuild.2017.06.007

[12] Ahmad MW, Mourshed M, Mundow D, Sisinni M, Rezgui Y. (2016). Building energy metering and environmental monitoring. A state-of-the-art review and directions for future research. Energy and Buildings 120: 85-102. https://doi.org/10.1016/j.enbuild.2016.03.059

[13] Celenza L, Dell'Isola M, Ficco G, Greco M, Grimaldi M. (2016). Economic and technical feasibility of metering and sub-metering systems for heat accounting. Int J En Ec \& Pol 6(3): 581-587, 2016.

[14] Bergero S, Cavalletti P, Michelini M. (2017). Analysis of thermal control and heat accounting economic convenience in typical Italian housing unit and climatic zones. International Journal of Heat and Technology 35(1): S64-S70. https://doi.org/10.18280/ijht.35Sp0109

[15] UNI EN 15459, Energy performance of buildings. Economic evaluation procedure for energy systems in buildings, 2008.

[16] European Commission, Commission Delegated Regulation (EU) 244/2012 of 16 January 2012, Supplementing Directive 2010/31/EU of the European Parliament and of the Council on the energy performance of buildings by establishing a comparative methodology framework for calculating cost-optimal levels of minimum energy performance requirements for buildings and building elements, 2012 .

[17] ISTAT, 15th Census of population and housing, Italy, 2011.

[18] UNI EN ISO 10349-3, Heating and cooling of buildings. Climatic data. Part 3: Accumulated temperature differences (degree-days) and other indices, 2016.

[19] Determining requirements and energy consumption of building-plant systems, Characterization of residential real estate park. CRESME Ricerche S.p.A., ENEA, Italy, Rep.RdS/2012/109, 2012.

[20] AEEG Resolution No. 103/2003, Guidelines for the preparation, execution and evaluation of the projects referred to art. 5, par. 1, of the Ministerial Decrees of 24 April 2001 and the definition of the criteria and modalities for the issue of energy efficiency certificates, Italy, 2003.

[21] Public works price of the Region Liguria, Department for Public Works, 2017.

[22] Decree 20 July 2012 of the Ministry of Justice No. 140 , Regulation determining the parameters for the liquidation of remuneration for professions regularly monitored by the Ministry of Justice pursuant to Article 9 of Decree-Law No. 1 of 24 March 2012, Italy, 2012.

[23] List of informative prices for civil works, Autonomous Province of Bolzano Alto Adige, 2016.

[24] Price list of the Region Piedmont: reference prices for works and public works in the Region Piedmont, 2016.

[25] Public works price of the Region Campania, Department for Public Works, 2013.

[26] Legislative Decree 27 February 2013, New regional price list for public works. Official Gazette of the Sicilian Region, 2013.

[27] Characterization of the National Building Park. Determination of building type for office use. ENEA,
Italy, ENEA Report RSE/2009/164, 2009.

[28] Corrado V, Ballarini I, Corgnati SP. (2014). Building Typology Brochure - Italy, TABULA Project.

[29] Law 30 April 1976, No. 373, Rules for the reduction of energy consumption for thermal use in buildings, Italy, 1976.

[30] Law 9 January 1991, No. 10, Standards for implementation of the national energy plan for rational use of energy, energy saving and development of renewable energy sources, Italy, 1991.

[31] Legislative Decree 19 August 2005, No. 192, Implementation of Directive 2002/91/EC on energy performance in buildings", Italy, 2005.

[32] UNI/TS 11300-1, Energy Performance of Buildings, Part 1: Evaluation of Energy Need for Space Heating and Cooling, Italy, 2014.

[33] UNI EN ISO 13789, Thermal performance of buildings. Transmission and ventilation heat transfer coefficients. Calculation method, 2008.

[34] UNI EN ISO 13370, Thermal performance of building. Heat transfer via the ground. Calculation methods, 2008.

[35] Decree 26 June 2015 of the Ministry of Economic Development, Applying the methods of calculating energy performance and definition of requirements and minimum standards of buildings, Italy, 2015.

[36] Corrado V, Ballarini I, Paduos S. (2013). Development of cost-optimal comparative methodology according to Directive 2010/31/EU. ENEA, Italy, Rep RdS/2013/144.

[37] Ministry of Economic Development, Clarifications on thermoregulation and heat accounting. Application of Legislative Decree 4-07-2014, no. 102, Article 9, paragraph 5, June 2017.

[38] Biele E, Santo DD, Tomassetti G. (2015). Analysis of the impact of thermostatic valves on the final consumption of users connected to the district heating networks of the mountain communities of the climatic zones $\mathrm{E}$ and $\mathrm{F}$. ENEA, Italy, Rep. Rds/PAR2014/081, 2015.

[39] UNI/TS 11300-2, Energy Performance of Buildings, Part 2: Evaluation of primary energy need and of system efficiencies for space heating, domestic hot water production, ventilation and lighting for non-residential buildings, Italy, 2014.

[40] Cavalletti P, Bergero S. (2016). The mean heat transmission coefficient as a new parameter to control heat transmission and mould growth in building refurbishing. J Civ Eng \& Arch Res 3(6): 1495-1502.

\section{NOMENCLATURE}

A

$b_{t r, x}$

$\mathrm{E}$

$\mathrm{H}_{\mathrm{A}}$

$\mathrm{H}_{\mathrm{D}}$

$\mathrm{H}_{\mathrm{g}}$

$\mathrm{H}_{\mathrm{ht}}$ gross projected area, $\mathrm{m}^{2}$

dimensionless adjustment factor between interior and adjacent zone energy need, kWh

heat transfer coefficient by transmission to adjacent buildings, $\mathrm{kW}$. $\mathrm{K}^{-1}$ direct heat transfer coefficient by transmission to the external environment, $\mathrm{kW} . \mathrm{K}^{-1}$

steady-state heat transfer coefficient by transmission to the ground, $\mathrm{kW} . \mathrm{K}^{-1}$ global heat transfer coefficient of the thermal zone, $\mathrm{kW} . \mathrm{K}^{-1}$ 

zone, $\mathrm{kW}$. $\mathrm{K}^{-1}$

$\mathrm{H}_{\mathrm{ve}}$

$\mathrm{n}$
$\mathrm{T}$ ventilation coefficient of the thermal zone, $\mathrm{kW} . \mathrm{K}^{-1}$ thermal transmittance, $\mathrm{W} \cdot \mathrm{m}^{-2} \cdot \mathrm{K}^{-1}$

\section{Greek symbols} through unconditioned spaces, $\mathrm{kW}$. $\mathrm{K}^{-1}$

dimensionless plant efficiency using time, $\mathrm{h}$ 